Article

\title{
From Water to Land: The Structural Construction and Molecu- lar Switches in Lungs during Metamorphosis of Microhyla fis- sipes
}

Liming Changa, b, Meihua Zhanga, Qiheng Chena, b, Jiongyu Liua, Wei Zhu ${ }^{a}{ }^{*}$, Jianping Jiang $^{\mathrm{a}, \mathrm{b}^{*}}$

a CAS Key Laboratory of Mountain Ecological Restoration and Bioresource Utilization $\mathcal{E}$ Ecological Restoration and Biodiversity Conservation Key Laboratory of Sichuan Province,

Chengdu Institute of Biology, Chinese Academy of Sciences, Chengdu 610041, China

b University of Chinese Academy of Sciences, Beijing 100049, China

${ }^{*}$ Corresponding authors: Jianping Jiang, E-mail: jiangjp@cib.ac.cn; Wei Zhu, E-mail: zhuwei@cib.ac.cn

Manuscript type: Original article 
Simple Summary: Metamorphosis is a critical process for most anurans to accomplish the transition from an aquatic life stage to a terrestrial life stage. During this process, numerous organ systems undergo rapid morphological and functional changes to adapt to new environments. Thus, amphibian metamorphosis has long been a paradigm for studying cell proliferation and differentiation, programmed cell death, and tissue remodeling. From an evolutionary perspective, the sequential molecular variations underlying these morphological and functional changes provide insight for understanding the historical adaptation of vertebrates to terrestrial environments. Air-breathing is a milestone event in the evolutionary history of vertebrates. Amphibians are the earliest tetrapods to adapt to a terrestrial environment, and their lungs play an indispensable role in enabling air respiration for most anuran species. Revealing the structural construction and molecular switches of lung organogenesis is essential to understand the realization of air-breathing function in anuran. However, the process of pulmonary stepwise maturation during metamorphosis has been overlooked in amphibians. In this study, we highlight the key steps of lung development as amphibians transition from water to land. It provides an insight into the stepwise adaptation of the vertebrate respiration system to air-breathing and provokes potential implications regarding the functional evolution of the tetrapod respiration system.

\begin{abstract}
Metamorphosis is a critical process for most anurans to transition from water to land. The appearance of air-breathing lungs occurs during the change in oxygen medium from water to air. Revealing the structural construction and molecular switches of lung organogenesis is essential to understand the realization of air-breathing function. In this study, histology and transcriptomics were combinedly conducted to explore these issues in Microhyla fissipes lungs during metamorphosis. During the pro-metamorphic phase, histological structure improving of the alveolar wall was accompanied by robust substrate metabolism and protein turnover. The lungs, at the metamorphic climax phase, are characterized by an increased number of cilia in the alveolar epithelial cells and collagenous fibers in the connective tissues, corresponding to the transcriptional upregulation of cilia and extracellular matrix-related genes. The post-metamorphic lungs strengthen the contracting function, as suggested by the thickened muscle layer and the upregulated expression of genes involved in muscle contraction. The blood-gas barrier is fully developed in adult lungs whose transcriptional features are tissue growth and differentiation regulation and immunity. Importantly, significant transcriptional switches of pulmonary surfactant protein and hemoglobin facilitate airbreathing. Our results illuminated four key steps of lung development for amphibians to transition from water to land.
\end{abstract}

Keywords: WGCNA; lung development; histological structure; molecular changes; amphibian 


\section{Introduction}

Metamorphosis is a critical process for most anurans to accomplish the transition from aquatic to terrestrial life (Burggren and Infantino 1994, Boatright-Horowitz and Simmons 1997). During this process, numerous organ systems undergo rapid morphological and functional changes to adapt to new environments (Frieden and Just 1970, Atkinson 1971). These include the resorption of larval-specific tissues such as gills and tail; formation of adult tissues such as hindlimbs, forelimbs, and lower jaw; and more commonly, remodeling of the larval organs (e.g., gastrointestinal tract, central nervous system, skin, kidney, and liver) (Shi and Ishizuya-Oka 2001, Furlow and Neff 2006, Brown and Cai 2007, Wang, Liu et al. 2019). Thus, amphibian metamorphosis has long been a paradigm to study cell proliferation and differentiation, programmed cell death, and tissue remodeling. From an evolutionary perspective, the sequential molecular variations underlying these morphological and functional changes provide a clue for understanding the historical adaptation of vertebrates to terrestrial environments (Burggren and Infantino 1994, Burggren and Warburton 2007, Liu, Zhao et al. 2016).

Air-breathing is a milestone event in the evolutionary history of vertebrates. Amphibians were the earliest tetrapods that adapted to the terrestrial environment, and their lungs play an indispensable role in enabling air respiration for most anuran species. Due to their complicated life cycle, metamorphosis of anuran larvae is accompanied by a shift in the primary respiration organs. The gills are responsible for breathing during the aquatic life stage; the skin is likely the most important organ in supporting the oxygen requirements during the metamorphic climax phase, while the lung is responsible for gas exchange during the terrestrial life stage (Burggren 1984, Wake 1986, Piiper and Scheid 1992, Burggren and Infantino 1994). One of the most interesting question is how the different organ systems are organized to function at different developmental stages in matching with the shift of respiration medium from water to air (Furlow and Neff 2006). During this process, functionalization of the lung is most fascinating as it resolves the challenge as the oxygen medium changes from water to air. Although the morphological and physiological functions of amphibian lung have received much attention, the microstructural changes and molecular mechanisms that underpin the functional maturation of lungs remain to be illuminated. For example, in addition to the alveolus architecture, the developmental levels of the capillary network, muscle tissue, and immune system in the lungs can also determine the efficiency of gas exchange. However, the process of stepwise maturation of these functions during metamorphosis have been overlooked. A systematic understanding of the structural construction and molecular switches in lungs during metamorphosis likely provides mechanistic insight into the stepwise adaptation of the vertebrate respiration system to air-breathing, and provokes potential implications regarding the functional evolution of the tetrapod respiration system.

Two groups of proteins, pulmonary surfactant-associated proteins (SFTPs) and hemoglobin (HB), play important roles in the maintenance of normal lung respiration. SFTPs are constitutive components of lung surfactant, with critical functions in reducing the surface tension of pulmonary alveoli and conferring innate immunity (Weaver and Whitsett 1991). The content of surfactant is an important indicator of lung function. HB is the carrier of oxygen and carbon dioxide in animals. Although erythrocytes are commonly not considered to be a component of lungs, they are functionally impartible from the respiration organs and lung maturation is accompanied by an increment in blood flux through the lungs. Thus, to some extent, quantifying the transcriptional levels of HB in lungs can reflect their respiratory efficiency (Antonini and Brunori 1970).

Although functional lungs have been detected in most anuran species at their adult phase, their contributions to the total respiration requirements vary among species. Xenopus laevis is the most familiar amphibian model for developmental studies. This animal still lives in an aquatic environment after metamorphosis, and correspondingly, its lungs are structurally simple, and present as oval sacs surrounded by a capillary net (Okada, Ishiko et al. 1962, Meban 1973, Rankin, Hong Thi et al. 2015). For most other frogs and toads (e.g., Pelophylax nigromaculatus and Bufo vulgaris) that live in a terrestrial 
environment after metamorphosis, their lungs are more complicated in morphology and significant in function, and correspondingly, their lungs are finely divided into many respiratory spaces and copiously distributed capillary networks (Okada, Ishiko et al. 1962). These amphibians, with a distinct aquatic and terrestrial life history, are more appropriate for studying the molecular basis of lung functionalization during metamorphosis.

Microhyla fissipes (Anura: Microhylidae) is a very good model for exploring anuran metamorphosis due to its representativeness as a land-dwelling species at the adult phase and its superiority in developing rate and transparency of tadpole skin (Fei, Ye et al. 2012, Liu, Zhao et al. 2016), and has got its complete embryonic developmental table (Wang, Zhao et al. 2017). Here, integrated histology (histological section and transmission electron microscope) and transcriptomics were conducted to study the critical cytological and molecular events associated with lung maturation during the pro-metamorphic (Stages 37-41), metamorphic climax (Stage 43), post-metamorphic (Stage 45), and adult phases. Then, we explored the developmental patterns by which the different cellular functions mature, as well as the metabolic processes that support the morphogenesis. This study highlights the role of lung development during metamorphosis in facilitating the transition of amphibians from water to land.

\section{Materials and Methods}

\subsection{Animal and Daily Culture}

The M. fissipes adults were collected from farmlands (E103.459885 ${ }^{\circ}$ N30.744614, 701 m) located in Shifang City, Sichuan Province, China, July 15, 2019. Adult male and female frogs were bred following the standard procedures for artificially induced spawning (Wang, Zhao et al. 2017) and egg production. Four egg clutches (ranging from 200 to 500 eggs) of $M$. fissipes were collected and placed into twelve aquatic containers (length $42 \times$ width $30 \times$ depth $10 \mathrm{~cm}$, water depth $=5 \mathrm{~cm}$ ) and hatched at $25 \pm 0.5^{\circ} \mathrm{C}$ (water temperature, light/dark $=12: 12 \mathrm{~h}$ ). The hatched larvae were fed a solution of boiled chicken egg yolk once a day for two days. Then, tadpoles were fed spirulina powder (China National Salt Industry Corporation) once a day, and water was replaced every two days. The developmental stages of tadpoles were identified according to the staging table reported by Wang et al. (2017) (Wang, Zhao et al. 2017).

\subsection{Experimental Design and Sampling}

This experiment was conducted to investigate amphibian lung development from the aquatic life stage to the terrestrial life stage. $M$. fissipes individuals were collected during the pro-metamorphic (Stages 37, 39, and 41), metamorphic climax (Stage 43), post-metamorphic (Stage 45), and adult phases (Figure 1A). After individuals were euthanized with Tricaine (MS-222), the lung tissues were collected for histological sections (both light and electron microscopy), micro-computed tomography, and RNA-seq. The animal procedures were approved by the Animal Care and Use Committee of Chengdu Institute of Biology (permit no. 2015-AR-JJP-01).

\subsection{Micro-computed tomography (micro-CT)}

After anesthetization by MS-222, tadpoles were fixed in $4 \%$ paraformaldehyde for 1 h. All specimens were scanned using a scanner (Quantum GXmicro-CT Imaging System, Per-kinElmer, Waltham, USA) at the herpetology lab, Chengdu Institute of Biology, Chinese Academy of Sciences, with the following parameters: scanning current, $70 \mathrm{eV} ; 10 \mu \mathrm{M}$; field of view: $36 \times 36 \mathrm{~mm}$ for acquisition, $25 \times 25 \mathrm{~mm}$ for reconstruction; scan duration, 15 $\mathrm{min}$. Scanning images of lung were segmented and color rendered using the 3D software Materialise Mimics (Materialise's interactive medical image control system, Materialise companies, Belgium). 


\subsection{Histological Analysis}

The method of histological sectioning followed the protocol described by Chang et al. (2021) (Chang, Wang et al. 2021). In brief, histological sections were stained with Masson trichrome stain for collagen fibers and myofibers. Section staining followed the instructions of the commercial kits purchased from Servicebio Technology Co., Ltd. (Wuhan, China). After sealing with resinene, the histological sections were analyzed using a Nikon E200 microscope equipped with an industrial digital camera (APTINA CMOS Sensor, San Jose, USA). For each stage, three biological replicants were conducted.

\subsection{Transmission Electron Microscopic (TEM) Observation}

Fresh lung tissues were collected and cut into small $\left(1 \mathrm{~mm}^{3}\right)$ blocks. After they were fixed in $3 \%$ glutaraldehyde $\left(6 \mathrm{~h}, 4^{\circ} \mathrm{C}\right)$, the tissue blocks were rinsed in $0.1 \mathrm{M}$ Sorensen's phosphate buffer (pH 7.4), 3 times (15 min each time), and postfixed for $2 \mathrm{~h}$ in $1 \%$ osmium tetroxide in the same buffer. The tissue blocks were rinsed again and dehydrated using a graded series of ethanol $(30,50,70,80,95$, and 100\%, 20 min for each grade). After penetration with a mixture of acetone and EMBed 812 overnight at $37^{\circ} \mathrm{C}$, tissue blocks were embedded in EMBed 812. The embedding models with resin and samples were put into a $65{ }^{\circ} \mathrm{C}$ oven to polymerize for more than $48 \mathrm{~h}$. The resin blocks were cut into $60-80 \mathrm{~nm}$ ultrathin sections using an ultramicrotome (Leica UC7) and Diamond slicer (Daitome Ultra $\left.45^{\circ}\right)$. Ultrathin sections were fished out onto the 150 meshes cuprum grids with formvar film and stained in $2 \%$ uranium acetate saturated alcohol solution for $8 \mathrm{~min}$. After rinsing with $70 \%$ ethanol and ultrapure water, the ultrathin sections were stained in $2.6 \%$ lead citrate for $8 \mathrm{~min}$. After drying using filter paper, the cuprum grids were put into the grid board and dried overnight at room temperature. The cuprum grids were observed under TEM (Hitachi, HT7800/HT7700) operating at $60 \mathrm{kV}$ and photographed using a CCD digital camera.

\subsection{Transcriptomic Analyses}

In order to meet the minimum tissue amount for RNA extraction, 30, 30, 20, 15, and 10 individual lungs were merged as one sample at Stages 37, 39, 41, 43, and 45, respectively; three samples were prepared for each phase. For adults, the lungs of two males and one female were collected, and each lung was used as one sample. The samples were fresh frozen in liquid nitrogen and stored in a $-80^{\circ} \mathrm{C}$ freezer until RNA extraction. Total RNA extraction followed the protocol of TRIzol (Life Technologies Corp., Carlsbad, CA, USA). For each sample, $1 \mu \mathrm{g}$ RNA was used for library construction with a NEBNext ${ }^{\circledR} \mathrm{Ultra}^{\mathrm{TM}}$ RNA Library Prep Kit for Illumina ${ }^{\circledR}$ (NEB, USA). Sequencing was conducted on an Illumina Hiseq 2000 platform from Biomarker Technologies Co. Ltd., and paired-end reads were generated. The sequencing data in this study have been submitted to the Genome Sequence Archive (GSA, https://bigd.big.ac.cn/gsa/) under accession number PRJCA004230. Clean data were obtained by removing reads from the raw data that contained adapter and ploy-N, and low-quality reads. Transcriptome was assembled with Trinity (Grabherr, Haas et al. 2011) and annotated by querying against NR (NCBI nonredundant protein sequences), Pfam (protein family), KOG/COG/eggNOG (clusters of orthologous groups of proteins), Swiss-Prot (a manually annotated and reviewed protein sequence database), KEGG (Kyoto Encyclopedia of Genes and Genomes), and GO (Gene Ontology). Gene expression levels were estimated by RSEM (Li and Dewey 2011). The differential expression analyses between developmental stages were performed using the DESeq2 based on the negative binomial distribution (Love, Huber et al. 2014). Differentially expressed genes (DEGs) should meet $q<0.05$ after Benjamini and Hochberg's correction.

\subsection{Weighted Correlation Network Analysis (WGCNA)}

The gene clusters or modules potentially associated with each developmental stage were screened out by WGCNA (Langfelder and Horvath 2008). WGCNA is a systematic biological method used to construct a scale-free network based on gene expression 
profiles. First, we constructed a similarity matrix that calculated the absolute value of the Pearson's correlation coefficient between two genes based on expression data. Then, the similarity matrix was converted into an adjacency matrix, where the $\beta$ value was the soft threshold (power value) to enhance strong connections and to disregard weak correlations between genes in the adjacency matrix. Next, the adjacency matrix was converted into a topological matrix (TOM) to describe the association strength between the genes. The TOM was used as the input for the hierarchical clustering analysis of genes, and the dynamic tree cut algorithm was applied to identify network modules. The most representative genes, module eigengenes (MEs), were the first principal components, representing the overall level of gene expression in individual modules. Module membership (MM) was measured using Pearson's correlation coefficient of the expression profile of one gene in all samples and one ME. Lastly, the gene significance (GS) value was used to evaluate the gene with developmental stage information (Additional File S1). The higher the value of GS, the better representativeness it holds for a specific developmental stage. Thus, the expression profile of DEGs was used to construct a free-scale network and identify significant modules related to developmental stage traits. We screened the core genes (GS $>0.7$ and $\mathrm{MM}>0.7$ ) to reveal the biological function of modules.

\section{Results}

\subsection{Structure Observations}

The lungs of $M$. fissipes increased in volume and became complicated in morphological and histological structure with the proceeding of metamorphosis (Figure 1B). The prometamorphic lung (S37-41) presented a simple sac-like structure, which was comprised of a single layer of epithelium surrounded by a thin layer of mesenchyme. The most prominent feature was the thickening of the alveolar wall during this stage. During the metamorphic climax phase, increasing alveolar septa separated the lung into several irregular compartments. Histologically, there was an obvious increment on the number of collagenous fibers at the mesenchyme layer, which were stained in blue by Masson's trichrome method (Figure 1C). At post-metamorphosis, the amount of collagenous fibers in the mesenchyme layer decreased dramatically. Instead, a thin but integral smooth muscle layer (stained in red) was formed in the lungs (Figure 1C). In adults, the lung wall was characterized by the formation of septa, which was rich in pulmonary blood vessels and a series of peripheral alveolar sacs originated from these septa. The electron microscopy results suggested that the alveolar epithelial cells appeared to be oval-like during the pro-metamorphic phase and metamorphic climax phase, and then matured as squamous cells with irregular shapes during the post-metamorphosis and adult phases (Figure 1D). With the proceeding of metamorphosis, the cilia of alveolar epithelial cells grew in number and length, especially after the metamorphic climax (S43). The blood capillaries across the alveolar wall increased in number, resulting in reduced distances between alveolar epithelial and endothelial cells. Notably, the blood endothelial cells were surrounded by large alveolar epithelial cells in the adult lungs, which was suggestive of a mature blood-gas barrier (Figure 1D). Structurally, the lung showed stepwise maturation within four developmental phases. 


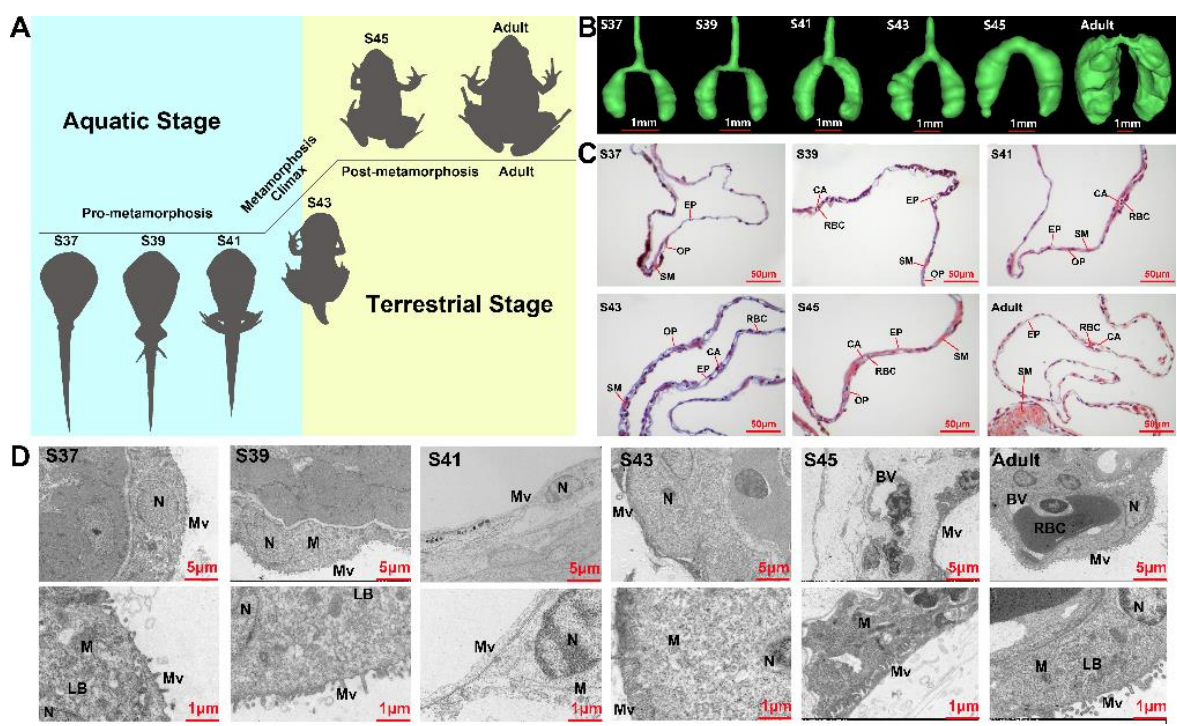

Figure 1. Structural variations of lung with developmental stages. (A) Experimental design for this study. Six developmental stages comprising four developmental phases (prometamorphic, metamorphic climax, post-metamorphic, and adult phases) with their corresponding habitats. (B) Morphological appearance form under Micro-CT in different developmental stages. (C) histological and (D) ultrastructural characteristics of lung in different developmental stages: CA, capillary; EP, epithelium; RBC, red blood cell; SM, smooth muscle; $\mathrm{OP}$, outer pleura. LB, lamellar body; $\mathrm{M}$, mitochondria; $\mathrm{Mv}$, microvillus; $\mathrm{N}$, nucleus.

The electron microscopy results suggested that the alveolar epithelial cells appeared to be oval-like during the pro-metamorphic phase and metamorphic climax phase, and then matured as squamous cells with irregular shapes during the post-metamorphosis and adult phases. With the proceeding of metamorphosis, the cilia of alveolar epithelial cells grew in number and length, especially after the metamorphic climax Stage 43 (S43). The blood capillaries across the alveolar wall increased in number, resulting in reduced distances between alveolar epithelial and endothelial cells. Notably, the blood endothelial cells were surrounded by large alveolar epithelial cells in the adult lungs, which was suggestive of a mature blood-gas barrier (Figure 1D).

\subsection{Functional Analysis of Co-Expressed Modules}

In this study, a total of 11,641 genes were identified to be differently expressed between stages (pairwise comparisons) (Figure 2A). WGCNA was conducted for these DEGs, and then were classified into 13 gene clusters/modules according to their expression patterns across stages. Among the 13 clusters, 3 modules, 1 module, 1 module, and 1 module showed significant associations $(\mathrm{R} 2>0.7$ and $\mathrm{p}<0.001)$ with pro-metamorphic, metamorphic climax, post-metamorphic, and adult phases, respectively (Figure 2B). Therefore, these gene modules featured the corresponding phases.

The featured gene modules of different developmental phases were queried against the KEGG and Reactome database for functional enrichment analyses (Figure 2C). The results showed that the featured gene modules of the pro-metamorphic phase were enriched in the substance metabolism and immunity. During the metamorphosis climax, the feature gene modules of highlighted ECM remodeling (i.e., ECM organization, collagen formation, and signaling by MET) and ciliogesis. The featured gene modules of post-metamorphic lungs highlighted muscle contraction, substance metabolism, and energy metabolism. The featured gene modules of adult lungs were enriched in substance metabolism, regulation of proliferation and differentiation, pulmonary circulation, and immunity. 
A

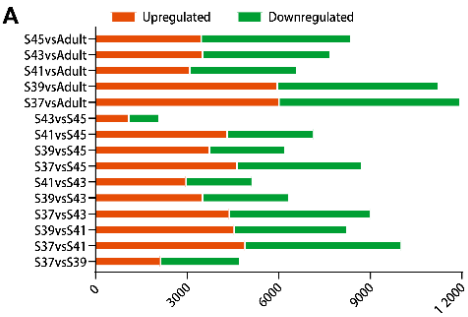

B

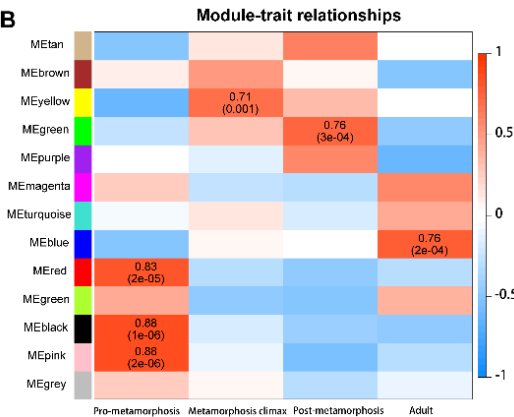

C

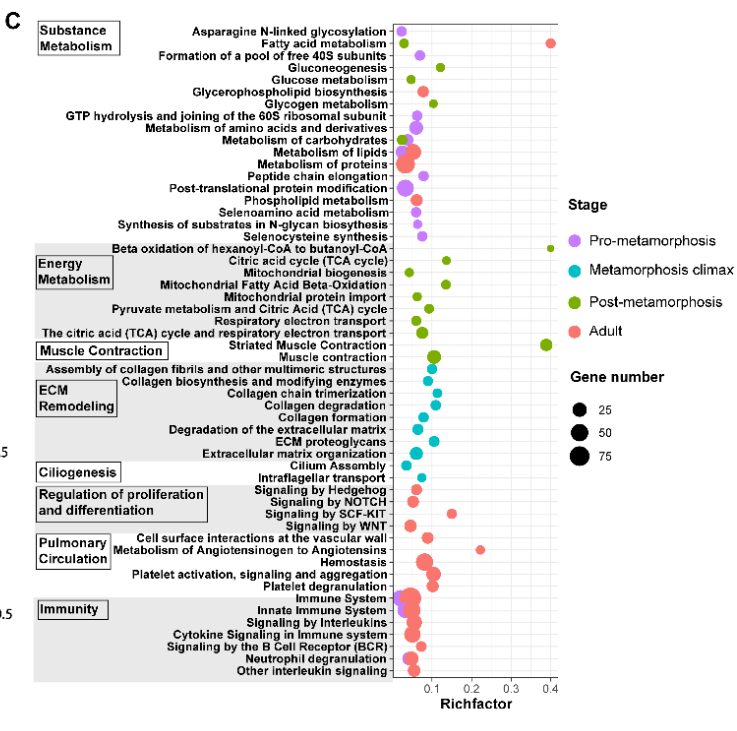

Figure 2. WGCNA and functional enrichment of gene modules. (A) Bar graph of the DEGs identified in all pairwise comparisons of stages; (B) Heatmap of correlations between module eigengenes and developmental phases. The color scale indicates the strength of correlation; (C) Dot plots of main functional items of enriched gene modules (FDR < 0.05) in different developmental stages.

Furthermore, we explored the variation patterns of featured genes of different developmental phases. In pro-metamorphic phase, we identified 38, 15, 17, and 25 featured genes involved in protein turnover (i.e., ribosomal component and proteolysis-related genes), lipid metabolism, amino acid metabolism, and carbohydrate metabolism, respectively (Figure 3). Their expression in lungs was maintained at relatively high levels at prometamorphic phase (S37, S39, and S41), and then downregulated after the metamorphic climax phase. In metamorphic climax, the featured genes include 22 and 6 genes involved in ECM and cilium construction, respectively. Their expression levels peaked at the metamorphic climax phase (Figure 4). Noticeably, there were six mitotic genes that belonged to this gene module (Figure 4). The featured genes of post-metamorphic lungs comprise 11, 21, and 28 genes enriched for substrate metabolism, energy metabolism (i.e., ATP synthase, NADH dehydrogenase, and ADP/ATP translocase), and muscle contraction (i.e., tropomyosin, myosin, filamin, and myozenin), respectively. These genes had the highest transcription during the post-metamorphic phase (Figure 5). A total of 29, 16, and 14 featured genes of adult lungs involved in immunity, metabolic, and tissue growth and differentiation regulation-related pathways (i.e., Wnt and Notch signaling pathways). These genes showed gradually upregulated transcription in the lungs with the maturation of $M$. fissipes (Figure 6). 


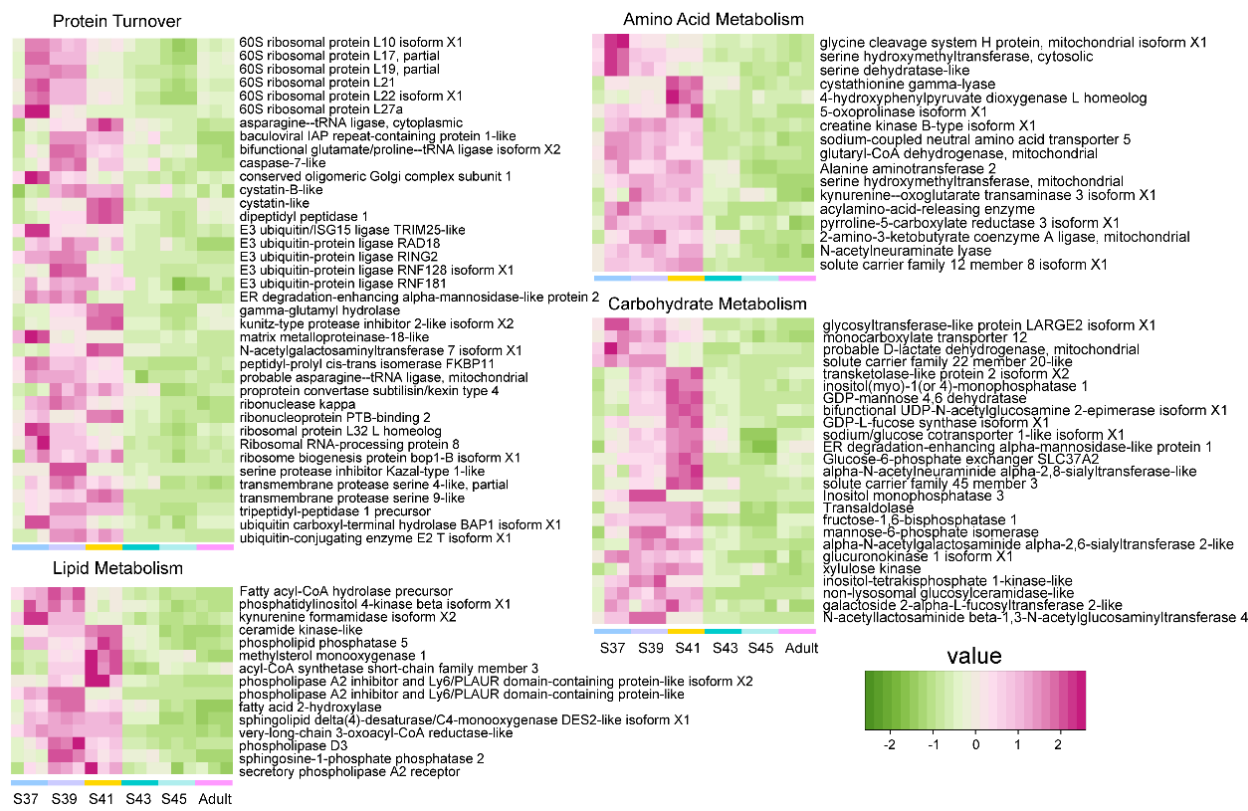

Figure 3. The featured genes during the pro-metamorphic phase. Variation patterns of genes involved in protein turnover, lipid metabolism, amino acid metabolism, and carbohydrate metabolism.

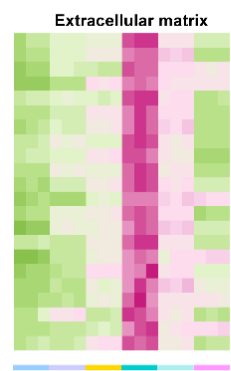

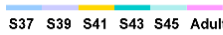

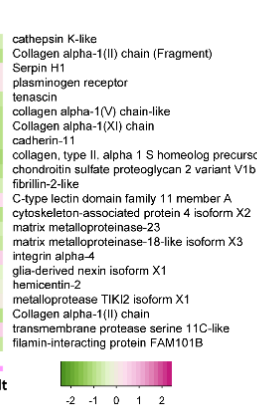

2,10
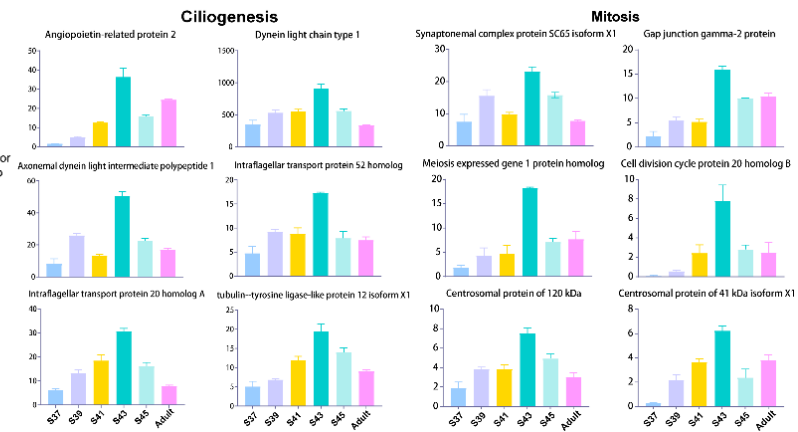

Figure 4. The featured genes during the metamorphic climax phase. Heat maps presenting the variation patterns of genes involved in ECM construction, bar plots presenting the variation patterns of genes involved in ciliogenesis and mitosis, respectively.

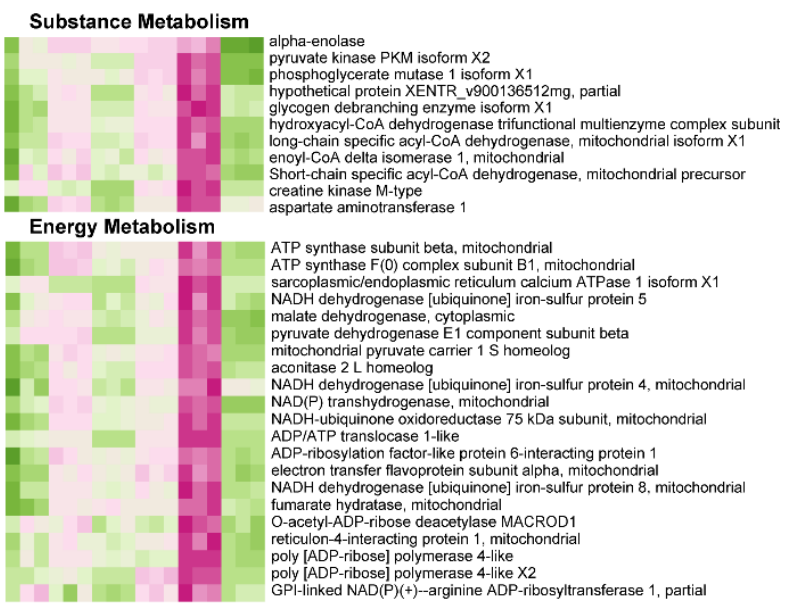

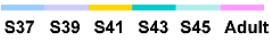

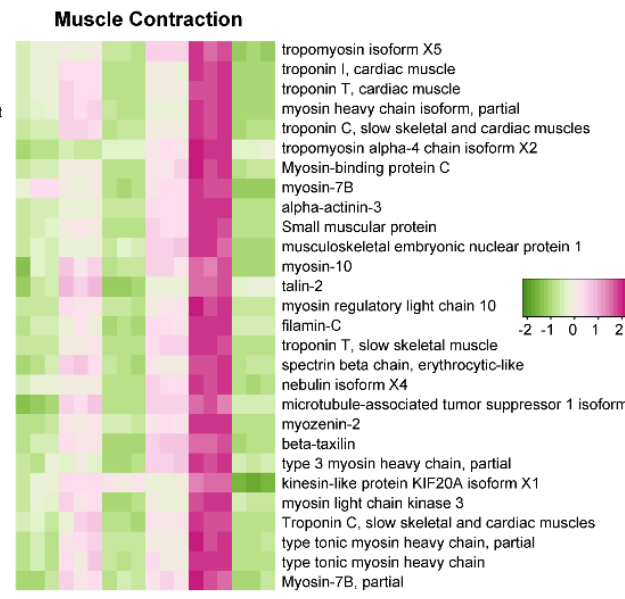

S37 S39 S41 S43 \$45 Adult

Figure 6. The featured genes in the adult phase. Heat maps of variation patterns of genes involved in immunity, pulmonary circulation, and tissue growth and 
differentiation regulation.
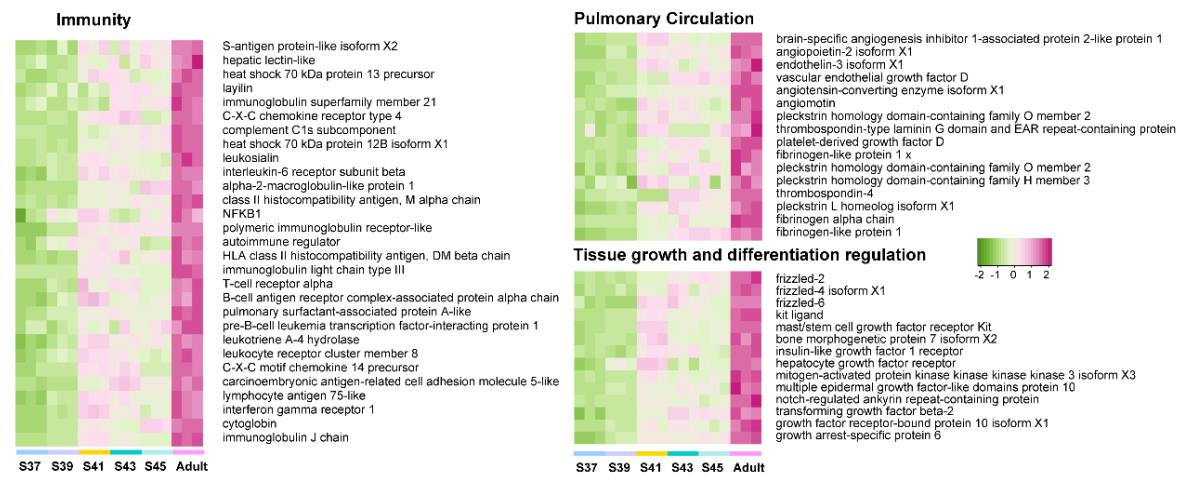

\subsection{Transcriptional Switches of Respiration Functional Proteins}

A total of five SFTP transcripts are identified in this study: SFTPA1-like, SFTPA2like, SFTPB, SFTPC, and SFTPD-like, and they present different patterns with stages (Figure 6). The transcriptional levels of SFTPA1-like and SFTPB increased as metamorphosis proceeded and peaked in adult lungs. The transcription of SFTPC dropped to the lowest level during the metamorphic climax, and then increased with the maturation of lungs. The transcription of SFTPD-like and SFTPA2-like peaked at Stage 41, and then decreased to an undetectable level during the metamorphic climax and adult phases, respectively.
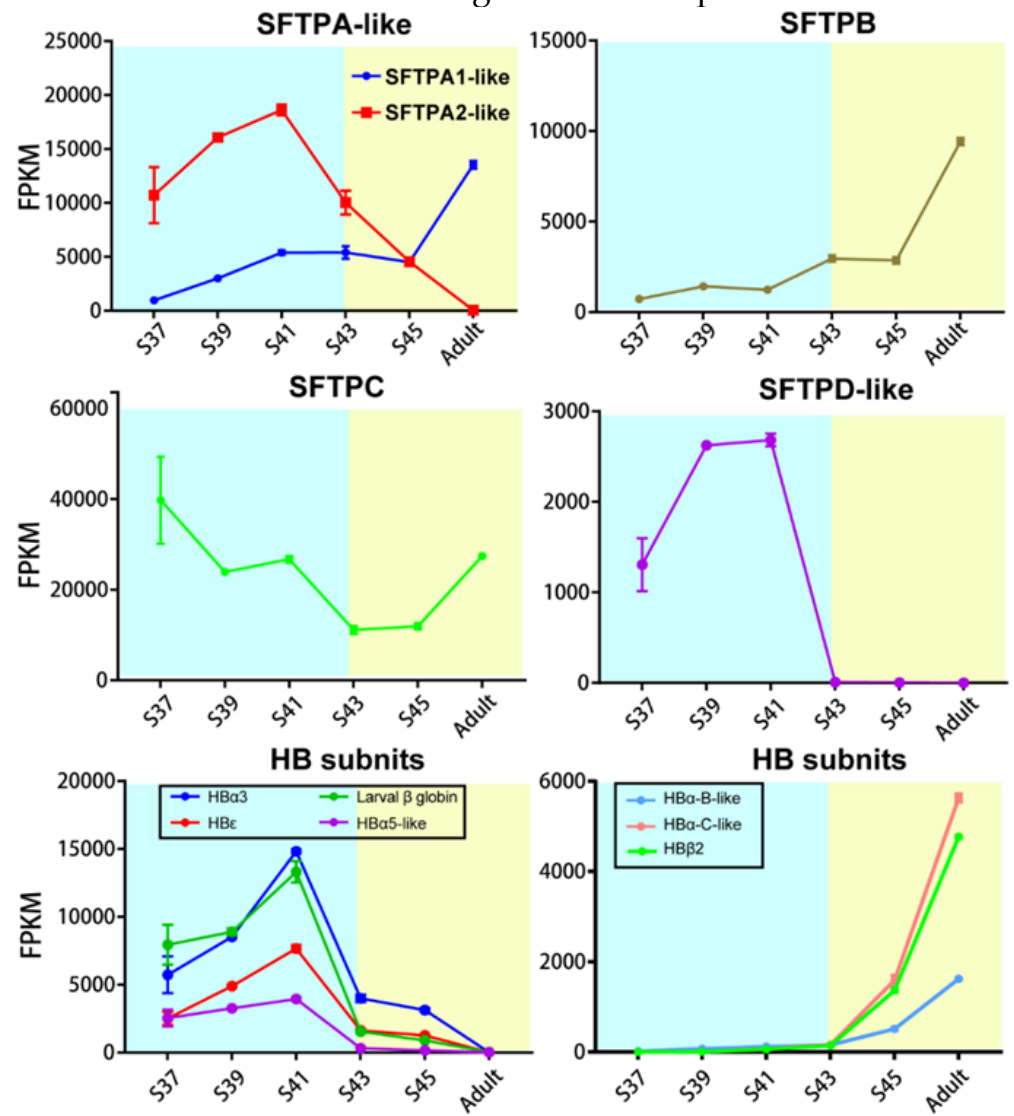

Figure 7. Transcriptional variation patterns of SFTPs and HBs subunits in lung. Blue and yellow background representing the aquatic and terrestrial phase, respectively.

There are seven transcripts of HB subunit identified in this study, and they present different patterns with stages (Figure 6). The transcriptional levels of $\mathrm{HB} \alpha 3, \mathrm{HB} \varepsilon$, and larval $\beta$ globin peaked in the late pro-metamorphic phase (Stage 41), and then decreased dramatically during the metamorphic climax phase, and maintained extreme low levels at the terrestrial life stage. In contrast, the transcriptional levels of $\mathrm{HB} \alpha 5, \mathrm{HB} \alpha$-B-like, $\mathrm{HB} \alpha-\mathrm{C}$-like, and $\mathrm{HB} \beta 2$ were maintained at extremely low levels during the pro- 
metamorphic phase, and then sharply upregulated during the metamorphic climax phase and peaked in adult lungs.

\section{Discussion}

\subsection{Rapid Growth and Robust Substrate Metabolism of Lungs during the Pro-Metamorphic Phase}

The pro-metamorphic phase is a thoroughly aquatic life stage of $M$. fissipes larval. During this phase, although the lungs have been ventilated (Figure 1B), they possess a structurally simple blood-gas barrier lacking alveolar septum with few capillaries (Figure 1C). As the blood-gas barrier is the structural basis of gas exchange, our results suggest that lung function is immature at this stage. However, the pro-metamorphosis phase is devoted to rapid somatic growth for tadpoles (Wang, Zhao et al. 2017). Although the lungs are considered to be a terrestrial breathing organ in amphibians, rapid growth in size occurred during the pro-metamorphosis phase. This was accompanied with gradual thickening of the alveolar wall (Figure 1C). Consistent with these morphological changes, the lungs of pro-metamorphic larvae showed robust transcription of genes in protein turnover, substrate metabolism, and surfactant metabolism (Figure 3). Protein turnover, which refers to protein synthesis and breakdown, is always extensive during rapid cell growth (Hawkins 1991). As growth rates increase, both whole-animal protein synthesis and degradation rates increase linearly; growth occurs because of the preponderance of synthesis over degradation (Houlihan, Hall et al. 1988). Protein turnover is the most energy-resource intensive process in cells, and thus accelerated protein metabolism relies on coupled upregulation of substrate metabolism, including lipid, amino acid, and carbohydrate metabolism (Figure 3). Accordingly, robust substrate metabolism might be a key event in facilitating lung growth during the pro-metamorphic phase.

\subsection{Construction of Extracellular Matrix and Accelerated Development of Lungs during the Metamorphic Phase}

Amphibian larvae begin to transform from an aquatic environment to a juvenile terrestrial environment during the metamorphic climax phase. This means that their lungs begin to morphologically and functionally mature during this phase. The lungs of $M$. fissipes larvae underwent dramatical morphological changes during the metamorphic climax phase, with increased extracellular collagenous fibers (Figure 2). Extracellular collagenous fibers or other ECM components are significant in directing rapid organogenesis in developing animals (Zhou, Horowitz et al. 2018). During the process, ECM interacts with cells to regulate diverse functions, including proliferation, migration, and differentiation (Bonnans, Chou et al. 2014). Consistent with histological observations, the metamorphic lungs showed transcriptional upregulation of genes involved in ECM and cilium construction (Figures $2 \mathrm{C}$ and $4 \mathrm{~A}, \mathrm{~B}$ ). ECM is a highly dynamic structure that is present in all tissues, particularly in developing organs (Hynes 2009, Bonnans, Chou et al. 2014). In our study, the ECM-related genes whose translation peaked during the metamorphic climax phase included matrix metalloproteinases (MMPs), elastin, and collagen (Figure 4A). MMPs are the main enzymes involved in ECM remodeling (Gross and Lapiere 1962, Lu, Takai et al. 2011). Their proteolytic actions are crucial to organogenesis and branching morphogenesis. Elastin and collagen are constitutive components of ECM, responsible for ECM stiffness in neonatal lungs and mediating the LRP5/TIE2 pathway to promote lung development in mice (Mammoto, Jiang et al. 2013, Liu, Young et al. 2014). In addition to ECM, our results suggested that the metamorphic lungs had more developed cilia in their alveolar epithelial cells (Figure 1D) and upregulation of cilium-related genes was another major transcriptional feature of the metamorphic lungs (Figure 4B). Cilia are an important structural basis for lung alveolar epithelial cells to increase the area of gas exchange, which hold a protective coat of mucus to the epithelium and facilitate the cellular secretory function. It is worthwhile mentioning that the mitotic genes showed prominent transcriptional 
upregulation (Figure 4C). This was suggestive of coupled ECM construction and cell proliferation of lung morphogenesis during the metamorphic climax phase.

\subsection{Reinforce of Muscle Function in Post-Metamorphic Lungs}

During the post-metamorphic phase, $M$. fissipes rely on air-breathing completely. The lungs during this phase have a relatively complicated structure, with distinctive inner epithelium, outer pleura, and scattered strands of connective tissue (Figure 2). The most prominent morphological improvement is the increased smooth muscle fibers in lung during this phase (Figure 2). Ancestrally, smooth muscle was likely involved in tension regulation, and may be involved in deflation and function largely to maintain the internal lung structure in amphibians (Cieri 2019). In support of our morphological observations, the major translational feature during this phase was the robust expression of genes involved in muscle function and energy metabolism (Figures $2 \mathrm{C}$ and $5 \mathrm{~A}$ ). These genes included tropomyosin, myosin, filamin, and myozenin, which are constitutive components of muscle fibers (Pollard and Goldman 2018). Meanwhile, enhanced substrate metabolism and energy metabolism might provide the energy to support smooth muscle contraction during the respiratory process. This means that the capacity of active respiration is likely improved comprehensively during this phase.

\subsection{Transcriptional Switches of Respiration Functional Proteins during the Metamorphic Climax Phase}

Pulmonary surfactant is a lipoprotein complex (phospholipoprotein) synthesized by alveolar cells, with a key role in maintaining respiratory function. There are at least four types of surfactant proteins in vertebrates, i.e., SFTPA, SFTPB, SFTPC, and SFTPD, making up 8-10\% of the surfactant (King 1982, Longo, Bisagno et al. 1993, Goerke 1998, Chroneos, Sever-Chroneos et al. 2010, Bourbon 2019). SFTPs are classified into two groups according to their hydrophobicity properties. The hydrophobic proteins including SFTPB and SFTPC, which are primarily involved in the prevention of alveolar collapse (Weaver and Conkright 2001), while hydrophilic SFTPA and SFTPD belong to the C-type lectin family (collectins), characterized with an N-terminal collagen-like domain and a C-terminal carbohydrate recognition domain that allows binding to various types of macromolecules, pathogens and allergens, and play a vital role in host defense (Wright 2005, Chroneos, Sever-Chroneos et al. 2010). In this study, the transcription of SFTPA1-like, SFTPA2-like, SFTPB, SFTPC, and SFTPD-like were identified in M. fissipes (Figure 6).

SFTPA belong to the most abundant proteins of pulmonary surfactant, which is involved in both host defense and surfactant-related functions. SFTPA has been identified in most vertebrates including lungfish, frog, chicken, mouse, monkey, human, et al. It showed high homology with $64 \%$ of the amino acid sequence being conserved in these species overall (Bourbon 2019). It was generally considered that SFTPA was encoded by single gene in most species except in primates and humans with two functional genes (Sftpa1 and Sftpa2) (Silveyra and Floros 2013). Several previous studies have identified functional differences between SFTPA1 and SFTPA2 in a variety of innate immunity and surfactant related functions including cytokine production (Wang, Umstead et al. 2002, Huang, Wang et al. 2004), modulation of surfactant secretion (Wang, Bates-Kenney et al. 2004), and phagocytosis by alveolar macrophages(Mikerov, Wang et al. 2007, Mikerov, Umstead et al. 2008). With the genome data increasement, two coding genes of SFTPA (Sftpa1 and Sftpa2) were also identified in amphibian (e.g., X. tropicalis) (Hellsten, Harland et al. 2010) and avian, such as Gallus domestiaus (Hillier, Miller et al. 2004), Alectura lathami, Ceuthmochares aereus, et al (Feng, Stiller et al. 2020), while their functional research are lacking. In this study, two coding genes of SFTPA were identified in the lungs of $M$. fissipes and the expression of SFTPA1-like and SFTPA2-like showed opposite variation trends with the progression of metamorphosis. This might be an important aspect for coping with the shift of pathogen groups after transition from aquatic to air breathing.

SFTPB is the most ancient member of SFTP family and is widely present from bony fishes to tetrapods. Sftpb gene tends to be more broadly expressed in multiple tissues of 
ray-finned fishes and lungfishes, while is specifically expressed in lungs of tetrapods (Wang, Wang et al. 2021). It rearranges lipid molecules in the fluid lining of lung so that the alveoli can more easily inflate (Longo, Bisagno et al. 1993), and its absence inevitably leads to lung conditions, with the most common being acute respiratory distress syndrome (Hawgood, Derrick et al. 1998). Consistent with its significance to air breathing, its transcription in the lungs increased with the maturation of $M$. fissipes.

SFTPC is a genetic innovation for air-breathing in vertebrate (Wang, Wang et al. 2021). It is a hydrophobic membrane protein that increases the rate that surfactant spreads over the surface, and is a requirement for the proper biophysical function of the lungs (Cochrane and Revak 1991, Galla, Bourdos et al. 1998, Pryhuber 1998). Humans and animals that are born lacking SFTPC tend to develop progressive interstitial pneumonitis (Arrkan-Ayyıldız, Caglayan-Sozmen et al. 2014). In M. fissipes lungs, the transcriptional level of SFTPC, despite fluctuating, was maintained at a considerable level across the larval and adult stages (Figure 6), suggesting that SFTPC was constitutive for lung development and functionalization.

Similar to SFTPA, SFTPD plays important roles in the host defense against infectious microorganisms and in regulating the innate immune response to a variety of pathogenassociated molecular patterns (Leth-Larsen, Garred et al. 2005). Interestingly, its expression suddenly dropped to extremely low levels after the metamorphic climax phase in $M$. fissipes lung. It is possible that there are some other proteins or other SFTPD subtypes that substitute their immune roles in lungs. In any case, our results suggested that the lungs of amphibians might experience functional remodeling during the metamorphic climax phase to achieve adaptation to air breathing.

$\mathrm{HB}$ is the protein responsible for oxygen transport in the red blood cells of most vertebrates. Although these proteins were not expressed in pneumonocytes, their richness in the lungs is a significant determinator of gas exchange efficiency. In all jawed vertebrates, erythrocytes produced at distinct developmental stages contain different forms of hemoglobin (Hardison 2012). Most species produce embryonic-specific hemoglobins in primitive erythroid cells from the yolk sac, some species produce a fetal-specific form in the liver, and all species make an adult hemoglobin in erythroid cells in the bone marrow (Maniatis, Fritsch et al. 1980, Karlsson and Nienhuis 1985, Hardison 2012). HB is a heterotetramer that consists of two $\alpha$-like globin and two $\beta$-like globin (Antonini and Brunori 1970, Perutz 1978). In humans, $\alpha$-like globin cluster contains the embryonic $\xi$ gene, and adult $\alpha 1$ and $\alpha 2$ genes, and the $\beta$-like globin cluster includes embryonic $\varepsilon$ gene, the fetal ${ }^{\mathrm{G}} \gamma$ and ${ }^{\mathrm{A}} \gamma$, and adult $\beta$ and $\delta$ genes. During early embryonic development, erythropoiesis transitions from yolk sac to the fetal liver, and the site of erythropoiesis is in bone marrow after birth. Accordingly, twice switches occur in the expression of genes from the globin cluster during these processes (Bauer, Kamran et al. 2012, Hardison 2012). In X. laevis, two cluster of globin genes switch from larval type to adult type during metamorphosis (Weber, Blum et al. 1991, Mukhi, Cai et al. 2010). A total of 13 HB subunit genes were identified from $X$. laevis genome, including $8 \alpha$-like globin genes (i.e., hba1, hba2, hba3, hba4, hba3-like, hba5-like, hbz, and hbe) and $5 \beta$-like globin genes (i.e., hbb2, hbb2-like, hbg1, hbg2, and hbd) (Session, Uno et al. 2016). In this study, we identified seven globin genes in $M$. fissipes, including three $\beta$-like globin genes and four $\alpha$-like globin genes. The adult-type HB subunits replaced the larval-type HB subunits during the metamorphic climax phase, which was considered to be an adaptation strategy for the change of respiration medium from water to air (Figure 6). This might be coupled with the shift of the respiration organ from the gill to the skin and lung. HB switching, coupled with the maturation of an air-breathing organ is worthy of further study.

\subsection{Completely Functional Maturation in Adult Lungs}

Microhyla fissipes adults experience a series of complex life activities such as courtship, reproduction, and hibernation, and they face diverse, complicated, and risky terrestrial environments. Air-breathing ability is a key factor for adapting to a terrestrial environment. Well-functioning and structured lungs improve respiratory efficiency and avoid 
risk environmental pathogens from the air during gas exchange. The histologic structure showed that the lungs were fully developed with complex alveolar septum (Figure 1C) and complete blood-gas barrier structure in adults of $M$. fissipes (Figure 1D). The WGCNA analysis indicated that the genes related to regulating tissue growth and differentiation (e.g., WNT, BMP, and Notch signaling pathways) increased their transcriptional activity (Figures 2C and 5B). It is evidenced that signaling interplay between BMPs and Notch, WNT, and Hippo signaling cascades co-regulate endothelial cell biology, of which BMP signaling is a core signaling cascade in endothelium during vascular development and homeostasis (García de Vinuesa, Abdelilah-Seyfried et al. 2016). In addition, signaling pathways activate, upregulated transcription of pulmonary circulation-related genes (e.g., angiogenesis and platelet production and activation) (Figure 5B). Angiopoietin, angiomotin, endothelin, and vascular endothelial growth factor D plays crucial roles in angiogenesis (Marconcini, Marchiò et al. 1999, Masaki 2004, Thiriet 2013). Their coordinated expression implies that the morphogenesis of blood vessels occurs during this period. Thrombocytes, nucleated hemostatic blood cells of amphibians, are regarded as the functional equivalent of enucleated mammalian platelets, which are involved in hemostasis and immunity (Arikan and Cicek 2014). The enhanced function of pulmonary circulation contributes to meet the higher ventilatory demand. However, increased ventilation frequency might bring a bigger immune pressure. Accordingly, the genes involved in immunity (innate immunity and adaptive immunity) present a robust transcriptional upregulation (Figure 5B), which guarantees the respiratory process. All in all, the growth- and development-related signal pathways were active in adult individuals, which facilitated structurally and functionally complete lungs for adapting to complex terrestrial environments.

\subsection{Evolutionary Inspiration from Development of $M$. fissipes Lung}

Rapid changes of $M$. fissipes lung in morphology and function during metamorphosis facilitate realization of air breathing. At aquatic life stage, the larval lungs have been ventilated (Figure 1B), which contributes positive buoyancy and facilitates larval locomotion in water (Rose and James 2013). Meanwhile the lungs possess a simple blood-gas barrier lacking alveolar septum with few capillaries (Figure 1C, D), which suggested low respiratory efficiency in lung at this stage. Thus, histologically and functionally, the larval lungs are more like swim bladders of fish at aquatic life stage. Conversely, at terrestrial life stage, $M$. fissipes lungs are highly vascularized and possess robust immunity, which means high efficiency of respiratory at this stage. It is evidenced that lungs and swim bladders are homologous organs (Wang, Wang et al. 2021). The development of $M$. fissipes lung might recapitulate the processes of air-breathing organs evolution from water to land. Therefore, revealing the structural construction and molecular switches of lungs during metamorphosis, to some extent, provided a cue to trace the evolution of lung in vertebrate.

\section{Conclusions}

In this study, our results highlighted the four key steps of lung develop for land dwelling: tissue rapid growth during the pro-metamorphic phase, structural construction and molecular switches during the metamorphic climax phase, increased smooth muscle contraction during the pro-metamorphic phase, and further morphogenesis and improved immunity in adults. This study highlights the role of lung development during metamorphosis in facilitating the transition of amphibians from water to land.

\section{Patents}

This section is mandatory.

Supplementary Materials: The following are available online at www.mdpi.com/xxx/s1, Table S1: Developmental phase information of each sample.

Funding: This work was supported by the Second Tibetan Plateau Scientific Expedition and Research Program (STEP) (Grant No. 2019QZKK05010503); Important Research Project of Chinese 
Academy of Sciences (KJZG-EW-L13); National Natural Science Foundation of China (31900327, 31471964); Construction of Basic Conditions Platform of Sichuan Science and Technology Department (2019JDPT0020).

Institutional Review Board Statement: The study was conducted according to the guidelines of the Declaration of Animal Care and Use Committee of Chengdu Institute of Biology, and approved by the Institutional Ethics Committee of Chengdu Institute of Biology (permit no. 2015-AR-JJP-01).

Informed Consent Statement: Not applicable.

Data Availability Statement: The sequencing data in this study have been submitted to the Genome Sequence Archive (GSA; https://bigd.big.ac.cn/gsa/) under accession number PRJCA004230.

Acknowledgments: We thank Chengxin Hu and Cheng Shen for their help on collecting frogs.

Conflicts of Interest: The authors declare no conflict of interest. The funders had no role in the design of the study; in the collection, analyses, or interpretation of data; in the writing of the manuscript, or in the decision to publish the results.

\section{References}

Antonini, E. and M. Brunori (1970). "Hemoglobin." Annual Review of Biochemistry 39(1): 977-1042.

Arıkan-Ayyıldız, Z., S. Caglayan-Sozmen, S. Isık, R. Deterding, M. K. Dishop, R. Couderc, R. Epaud, M. Louha and N. Uzuner (2014). "Survival of an infant with homozygous surfactant protein C (SFTPC) mutation." Pediatric Pulmonology 49(3): E112-E115.

Arikan, H. and K. Cicek (2014). "Haematology of amphibians and reptiles: a review." North-Western Journal of Zoology 10(1): 190209.

Atkinson, B. G. (1971). Patterns of macromolecular biosynthesis during amphibian metamorphosis. Proceedings of 7th Conference on Endocrinology and Metabolism, Univ. of Missouri Press Columbia, Mo.

Bauer, D. E., S. C. Kamran and S. H. Orkin (2012). "Reawakening fetal hemoglobin: prospects for new therapies for the $\beta$-globin disorders." Blood 120(15): 2945-2953.

Boatright-Horowitz, S. S. and A. M. Simmons (1997). "Transient "deafness" accompanies auditory development during metamorphosis from tadpole to frog." Proceedings of the National Academy of Sciences of the United States of America 94(26): 1487714882.

Bonnans, C., J. Chou and Z. Werb (2014). "Remodelling the extracellular matrix in development and disease." Nature Reviews Molecular Cell Biology 15(12): 786-801.

Bourbon, J. R. (2019). Pulmonary surfactant: biochemical, functional, regulatory, and clinical concepts, CRC press.

Brown, D. D. and L. Cai (2007). "Amphibian metamorphosis." Developmental biology 306(1): 20-33.

Burggren, W. (1984). Transition of respiratory processes during amphibian metamorphosis: from egg to adult. Respiration and metabolism of embryonic vertebrates: Satellite Symposium of the 29th International Congress of Physiological Sciences, Sydney, Australia, 1983. R. S. Seymour. Dordrecht, Springer Netherlands: 31-53.

Burggren, W. W. and J. R. L. Infantino (1994). "The Respiratory Transition from Water to Air Breathing During Amphibian Metamorphosis1." American Zoologist 34(2): 238-246.

Burggren, W. W. and S. Warburton (2007). "Amphibians as animal models for laboratory research in physiology." Ilar Journal 48(3): 260-269.

Chang, L., B. Wang, M. Zhang, J. Liu, T. Zhao, W. Zhu and J. Jiang (2021). "The effects of corticosterone and background colour on tadpole physiological plasticity." Comparative Biochemistry and Physiology Part D: Genomics and Proteomics 39: 100872.

Chroneos, Z. C., Z. Sever-Chroneos and V. L. Shepherd (2010). "Pulmonary Surfactant: An Immunological Perspective." Cellular Physiology and Biochemistry 25(1): 13-26.

Cieri, R. L. (2019). "Pulmonary Smooth Muscle in Vertebrates: A Comparative Review of Structure and Function." INTEGRATIVE AND COMPARATIVE BIOLOGY 59(1): 10-28.

Cochrane, C. G. and S. D. Revak (1991). "Pulmonary Surfactant Protein B (SP-B): Structure-Function Relationships." Science 254(5031): 566-568. 
Fei, L., C. Ye and J. Jiang (2012). Colored atlas of Chinese amphibians and their distributions. Chengdu, Sichuan Publishing House of Science \& Technology.

Feng, S., J. Stiller, Y. Deng, J. Armstrong, Q. Fang, A. H. Reeve, D. Xie, G. Chen, C. Guo, B. C. Faircloth, B. Petersen, Z. Wang, Q. Zhou, M. Diekhans, W. Chen, S. Andreu-Sánchez, A. Margaryan, J. T. Howard, C. Parent, G. Pacheco, M.-H. S. Sinding, L. Puetz, E. Cavill, Â. M. Ribeiro, L. Eckhart, J. Fjeldså, P. A. Hosner, R. T. Brumfield, L. Christidis, M. F. Bertelsen, T. Sicheritz-Ponten, D. T. Tietze, B. C. Robertson, G. Song, G. Borgia, S. Claramunt, I. J. Lovette, S. J. Cowen, P. Njoroge, J. P. Dumbacher, O. A. Ryder, J. Fuchs, M. Bunce, D. W. Burt, J. Cracraft, G. Meng, S. J. Hackett, P. G. Ryan, K. A. Jønsson, I. G. Jamieson, R. R. da Fonseca, E. L. Braun, P. Houde, S. Mirarab, A. Suh, B. Hansson, S. Ponnikas, H. Sigeman, M. Stervander, P. B. Frandsen, H. van der Zwan, R. van der Sluis, C. Visser, C. N. Balakrishnan, A. G. Clark, J. W. Fitzpatrick, R. Bowman, N. Chen, A. Cloutier, T. B. Sackton, S. V. Edwards, D. J. Foote, S. B. Shakya, F. H. Sheldon, A. Vignal, A. E. R. Soares, B. Shapiro, J. González-Solís, J. Ferrer-Obiol, J. Rozas, M. Riutort, A. Tigano, V. Friesen, L. Dalén, A. O. Urrutia, T. Székely, Y. Liu, M. G. Campana, A. Corvelo, R. C. Fleischer, K. M. Rutherford, N. J. Gemmell, N. Dussex, H. Mouritsen, N. Thiele, K. Delmore, M. Liedvogel, A. Franke, M. P. Hoeppner, O. Krone, A. M. Fudickar, B. Milá, E. D. Ketterson, A. E. Fidler, G. Friis, Á. M. Parody-Merino, P. F. Battley, M. P. Cox, N. C. B. Lima, F. Prosdocimi, T. L. Parchman, B. A. Schlinger, B. A. Loiselle, J. G. Blake, H. C. Lim, L. B. Day, M. J. Fuxjager, M. W. Baldwin, M. J. Braun, M. Wirthlin, R. B. Dikow, T. B. Ryder, G. Camenisch, L. F. Keller, J. M. DaCosta, M. E. Hauber, M. I. M. Louder, C. C. Witt, J. A. McGuire, J. Mudge, L. C. Megna, M. D. Carling, B. Wang, S. A. Taylor, G. Del-Rio, A. Aleixo, A. T. R. Vasconcelos, C. V. Mello, J. T. Weir, D. Haussler, Q. Li, H. Yang, J. Wang, F. Lei, C. Rahbek, M. T. P. Gilbert, G. R. Graves, E. D. Jarvis, B. Paten and G. Zhang (2020). "Dense sampling of bird diversity increases power of comparative genomics." Nature 587(7833): 252-257.

Frieden, E. and J. Just (1970). "Hormonal responses in amphibian metamorphosis." Biochemical actions of hormones 1: 1-52. Furlow, J. D. and E. S. Neff (2006). "A developmental switch induced by thyroid hormone: Xenopus laevis metamorphosis." Trends in Endocrinology and Metabolism 17(2): 38-45.

Galla, H. J., N. Bourdos, A. von Nahmen, M. Amrein and M. Sieber (1998). "The role of pulmonary surfactant protein C during the breathing cycle." Thin Solid Films 327-329: 632-635.

García de Vinuesa, A., S. Abdelilah-Seyfried, P. Knaus, A. Zwijsen and S. Bailly (2016). "BMP signaling in vascular biology and dysfunction." Cytokine \& Growth Factor Reviews 27: 65-79.

Goerke, J. (1998). "Pulmonary surfactant: functions and molecular composition." Biochimica et Biophysica Acta (BBA) - Molecular Basis of Disease 1408(2): 79-89.

Grabherr, M. G., B. J. Haas, M. Yassour, J. Z. Levin, D. A. Thompson, I. Amit, X. Adiconis, L. Fan, R. Raychowdhury, Q. Zeng, Z. Chen, E. Mauceli, N. Hacohen, A. Gnirke, N. Rhind, F. di Palma, B. W. Birren, C. Nusbaum, K. Lindblad-Toh, N. Friedman and A. Regev (2011). "Full-length transcriptome assembly from RNA-Seq data without a reference genome." Nature biotechnology 29(7): 644-652.

Gross, J. and C. M. Lapiere (1962). "COLLAGENOLYTIC ACTIVITY IN AMPHIBIAN TISSUES - A TISSUE CULTURE ASSAY." Proceedings of the National Academy of Sciences of the United States of America 48(6): 1014-\&.

Hardison, R. C. (2012). "Evolution of Hemoglobin and Its Genes." Cold Spring Harbor Perspectives in Medicine 2(12).

Hawgood, S., M. Derrick and F. Poulain (1998). "Structure and properties of surfactant protein B." Biochimica et Biophysica Acta (BBA) - Molecular Basis of Disease 1408(2): 150-160.

Hawkins, A. J. S. (1991). "Protein Turnover: A Functional Appraisal." Functional Ecology 5(2): 222-233.

Hellsten, U., R. M. Harland, M. J. Gilchrist, D. Hendrix, J. Jurka, V. Kapitonov, I. Ovcharenko, N. H. Putnam, S. Q. Shu, L. Taher, I. L. Blitz, B. Blumberg, D. S. Dichmann, I. Dubchak, E. Amaya, J. C. Detter, R. Fletcher, D. S. Gerhard, D. Goodstein, T. Graves, I. V. Grigoriev, J. Grimwood, T. Kawashima, E. Lindquist, S. M. Lucas, P. E. Mead, T. Mitros, H. Ogino, Y. Ohta, A. V. Poliakov, N. Pollet, J. Robert, A. Salamov, A. K. Sater, J. Schmutz, A. Terry, P. D. Vize, W. C. Warren, D. Wells, A. Wills, R. K. Wilson, L. B. Zimmerman, A. M. Zorn, R. Grainger, T. Grammer, M. K. Khokha, P. M. Richardson and D. S. Rokhsar (2010). "The Genome of the Western Clawed Frog Xenopus tropicalis." Science 328(5978): 633-636. 
Hillier, L. W., W. Miller, E. Birney, W. Warren, R. C. Hardison, C. P. Ponting, P. Bork, D. W. Burt, M. A. M. Groenen, M. E. Delany, J. B. Dodgson, A. T. Chinwalla, P. F. Cliften, S. W. Clifton, K. D. Delehaunty, C. Fronick, R. S. Fulton, T. A. Graves, C. Kremitzki, D. Layman, V. Magrini, J. D. McPherson, T. L. Miner, P. Minx, W. E. Nash, M. N. Nhan, J. O. Nelson, L. G. Oddy, C. S. Pohl, J. RandallMaher, S. M. Smith, J. W. Wallis, S. P. Yang, M. N. Romanov, C. M. Rondelli, B. Paton, J. Smith, D. Morrice, L. Daniels, H. G. Tempest, L. Robertson, J. S. Masabanda, D. K. Griffin, A. Vignal, V. Fillon, L. Jacobbson, S. Kerje, L. Andersson, R. P. M. Crooijmans, J. Aerts, J. J. van der Poel, H. Ellegren, R. B. Caldwell, S. J. Hubbard, D. V. Grafham, A. M. Kierzek, S. R. McLaren, I. M. Overton, H. Arakawa, K. J. Beattie, Y. Bezzubov, P. E. Boardman, J. K. Bonfield, M. D. R. Croning, R. M. Davies, M. D. Francis, S. J. Humphray, C. E. Scott, R. G. Taylor, C. Tickle, W. R. A. Brown, J. Rogers, J. M. Buerstedde, S. A. Wilson, L. Stubbs, I. Ovcharenko, L. Gordon, S. Lucas, M. M. Miller, H. Inoko, T. Shiina, J. Kaufman, J. Salomonsen, K. Skjoedt, G. K. S. Wong, J. Wang, B. Liu, J. Wang, J. Yu, H. M. Yang, M. Nefedov, M. Koriabine, P. J. deJong, L. Goodstadt, C. Webber, N. J. Dickens, I. Letunic, M. Suyama, D. Torrents, C. von Mering, E. M. Zdobnov, K. Makova, A. Nekrutenko, L. Elnitski, P. Eswara, D. C. King, S. Yang, S. Tyekucheva, A. Radakrishnan, R. S. Harris, F. Chiaromonte, J. Taylor, J. B. He, M. Rijnkels, S. Griffiths-Jones, A. Ureta-Vidal, M. M. Hoffman, J. Severin, S. M. J. Searle, A. S. Law, D. Speed, D. Waddington, Z. Cheng, E. Tuzun, E. Eichler, Z. R. Bao, P. Flicek, D. D. Shteynberg, M. R. Brent, J. M. Bye, E. J. Huckle, S. Chatterji, C. Dewey, L. Pachter, A. Kouranov, Z. Mourelatos, A. G. Hatzigeorgiou, A. H. Paterson, R. Ivarie, M. Brandstrom, E. Axelsson, N. Backstrom, S. Berlin, M. T. Webster, O. Pourquie, A. Reymond, C. Ucla, S. E. Antonarakis, M. Y. Long, J. J. Emerson, E. Betran, I. Dupanloup, H. Kaessmann, A. S. Hinrichs, G. Bejerano, T. S. Furey, R. A. Harte, B. Raney, A. Siepel, W. J. Kent, D. Haussler, E. Eyras, R. Castelo, J. F. Abril, S. Castellano, F. Camara, G. Parra, R. Guigo, G. Bourque, G. Tesler, P. A. Pevzner, A. Smit, L. A. Fulton, E. R. Mardis and R. K. Wilson (2004). "Sequence and comparative analysis of the chicken genome provide unique perspectives on vertebrate evolution." Nature 432(7018): 695-716.

Houlihan, D., S. Hall, C. Gray and B. Noble (1988). "Growth Rates and Protein Turnover in Atlantic Cod, Gadus morhua." Canadian Journal of Fisheries and Aquatic Sciences - CAN I FISHERIES AQUAT SCI 45: 951-964.

Huang, W., G. Wang, D. S. Phelps, H. Al-Mondhiry and J. Floros (2004). "Human SP-A genetic variants and bleomycin-induced cytokine production by THP-1 cells: effect of ozone-induced SP-A oxidation." American Journal of Physiology-Lung Cellular and Molecular Physiology 286(3): L546-L553.

Hynes, R. O. (2009). "The Extracellular Matrix: Not Just Pretty Fibrils." Science 326(5957): 1216-1219.

Karlsson, S. and A. W. Nienhuis (1985). "Developmental regulation of human globin genes." Annual Review of Biochemistry 54(1): 1071-1108.

King, R. J. (1982). "Pulmonary surfactant." Journal of Applied Physiology 53(1): 1-8.

Langfelder, P. and S. Horvath (2008). "WGCNA: an R package for weighted correlation network analysis." Bmc Bioinformatics 9.

Leth-Larsen, R., P. Garred, H. Jensenius, J. Meschi, K. Hartshorn, J. Madsen, I. Tornoe, H. O. Madsen, G. Sørensen, E. Crouch and U. Holmskov (2005). "A Common Polymorphism in the SFTPD Gene Influences Assembly, Function, and Concentration of Surfactant Protein D." The Journal of Immunology 174(3): 1532.

Li, B. and C. N. Dewey (2011). "RSEM: accurate transcript quantification from RNA-Seq data with or without a reference genome." BMC Bioinformatics 12(1): 323.

Liu, L., L. Zhao, S. Wang and J. Jiang (2016). "Research proceedings on amphibian model organisms." Zoological research 37(4): 237245.

Liu, S., S. M. Young and B. M. Varisco (2014). "Dynamic expression of chymotrypsin-like elastase 1 over the course of murine lung development." American Journal of Physiology-Lung Cellular and Molecular Physiology 306(12): L1104-L1116.

Longo, M. L., A. M. Bisagno, J. A. N. Zasadzinski, R. Bruni and A. J. Waring (1993). "A Function of Lung Surfactant Protein SP-B." Science 261(5120): 453-456.

Love, M. I., W. Huber and S. Anders (2014). "Moderated estimation of fold change and dispersion for RNA-seq data with DESeq2." Genome Biology 15(12).

Lu, P., K. Takai, V. M. Weaver and Z. Werb (2011) "Extracellular matrix degradation and remodeling in development and disease." Cold Spring Harbor perspectives in biology 3 DOI: 10.1101/cshperspect.a005058. 
Mammoto, T., E. Jiang, A. Jiang and A. Mammoto (2013). "Extracellular Matrix Structure and Tissue Stiffness Control Postnatal Lung Development through the Lipoprotein Receptor-Related Protein 5/Tie2 Signaling System." American Journal of Respiratory Cell and Molecular Biology 49(6): 1009-1018.

Maniatis, T., E. F. Fritsch, J. Lauer and R. M. Lawn (1980). "The molecular genetics of human hemoglobins." Annual Review of Genetics 14(1): 145-178.

Marconcini, L., S. Marchiò, L. Morbidelli, E. Cartocci, A. Albini, M. Ziche, F. Bussolino and S. Oliviero (1999). "c-fos-induced growth factor/vascular endothelial growth factor D induces angiogenesis in vivo and in vitro." Proceedings of the National Academy of Sciences 96(17): 9671-9676.

Masaki, T. (2004). "Historical review: Endothelin." Trends in Pharmacological Sciences 25(4): 219-224.

Meban, C. (1973). "Pneumonocytes in lung of Xenopus laevis." Journal of Anatomy 114(FEB): 235-244.

Mikerov, A. N., T. M. Umstead, X. Gan, W. Huang, X. Guo, G. Wang, D. S. Phelps and J. Floros (2008). "Impact of ozone exposure on the phagocytic activity of human surfactant protein A (SP-A) and SP-A variants." American journal of physiology. Lung cellular and molecular physiology 294(1): L121-130.

Mikerov, A. N., G. Wang, T. M. Umstead, M. Zacharatos, N. J. Thomas, D. S. Phelps and J. Floros (2007). "Surfactant Protein A2 (SPA2) Variants Expressed in CHO Cells Stimulate Phagocytosis of Pseudomonas aeruginosa More than Do SP-A1 Variants." Infection and Immunity 75(3): 1403-1412.

Mukhi, S., L. Q. Cai and D. D. Brown (2010). "Gene switching at Xenopus laevis metamorphosis." Developmental Biology 338(2): 117126.

Okada, Y., S. Ishiko, S. Daido, J. Kim and S. Ikeda (1962). "Comparative morphology of the lung with special reference to the alveolar epithelial cells. I. Lung of the amphibia." Acta tuberculosea Japonica 11: 63-72.

Perutz, M. F. (1978). "Hemoglobin Structure and Respiratory Transport." Scientific American 239(6): 92-125.

Piiper, J. and P. Scheid (1992). "Gas Exchange in Vertebrates Through Lungs, Gills, and Skin." Physiology 7(5): 199-203.

Pollard, T. D. and R. D. Goldman (2018). "Overview of the Cytoskeleton from an Evolutionary Perspective." Cold Spring Harbor Perspectives in Biology 10(7).

Pryhuber, G. S. (1998). "Regulation and Function of Pulmonary Surfactant Protein B." Molecular Genetics and Metabolism 64(4): 217228.

Rankin, S. A., T. Hong Thi, M. Wlizla, P. Mancini, E. T. Shifley, S. D. Bloor, L. Han, K. Vleminckx, S. E. Wert and A. M. Zorn (2015). "A Molecular Atlas of Xenopus Respiratory System Development." Developmental Dynamics 244(1): 69-85.

Rose, C. S. and B. James (2013). "Plasticity of lung development in the amphibian, Xenopus laevis." Biology Open 2(12): 1324-1335. Session, A. M., Y. Uno, T. Kwon, J. A. C. Hapman, A. Toyoda, S. Takahashi, A. Fukui, A. Hikosaka, A. Suzuki, M. Kondo, S. J. van Heeringen, I. Quigley, S. Heinz, H. Ogino, H. Ochi, U. Hellsten, J. B. Lyons, O. Simakov, N. Putnam, J. Stites, Y. Kuroki, T. Tanaka, T. Michiue, M. Watanabe, O. B. Ogdanovic, R. Lister, G. Georgiou, S. S. Paranjpe, I. Van Kruijsbergen, S. Q. Shu, J. Carlson, T. Kinoshita, Y. Ohta, S. Mawaribuchi, J. Jenkins, J. Grimwood, J. Schmutz, T. Mitros, S. V. Mozaffari, Y. Suzuki, Y. Haramoto, T. S. Yamamoto, C. Takagi, R. Heald, K. Miller, C. Haudenschild, J. Kitzman, T. Nakayama, Y. I. Zutsu, J. Robert, J. Fortriede, K. Burns, V. Lotay, K. Karimi, Y. Yasuoka, D. S. Dichmann, M. F. Flajnik, D. W. Houston, J. Shendure, L. DuPasquier, P. D. Vize, A. M. Zorn, M. Ito, E. M. Marcotte, J. B. Wallingford, Y. Ito, M. Asashima, N. Ueno, Y. Matsuda, G. J. C. Veenstra, A. Fujiyama, R. M. Harland, M. Taira and D. S. Rokhsar (2016). "Genome evolution in the allotetraploid frog Xenopus laevis." Nature 538(7625): 336-+.

Shi, Y. and A. Ishizuya-Oka (2001). Thyroid hormone regulation of apoptotic tissue remodeling: Implications from molecular analysis of amphibian metamorphosis. Progress in Nucleic Acid Research and Molecular Biology, Vol 65. K. Moldave. 65: 53-100.

Silveyra, P. and J. Floros (2013). "Genetic complexity of the human surfactant-associated proteins SP-A1 and SP-A2." Gene 531(2): 126-132.

Thiriet, M. (2013). Vascular Endothelium. Tissue Functioning and Remodeling in the Circulatory and Ventilatory Systems. M. Thiriet. New York, NY, Springer New York: 453-603.

Wake, M. H. (1986). Biology of Amphibians, American Scientist. 
Wang, G., S. R. Bates-Kenney, J.-Q. Tao, D. S. Phelps and J. Floros (2004). "Differences in Biochemical Properties and in Biological Function between Human SP-A1 and SP-A2 Variants, and the Impact of Ozone-Induced Oxidation." Biochemistry 43(14): 4227-4239. Wang, G., T. M. Umstead, D. S. Phelps, H. Al-Mondhiry and J. Floros (2002). "The effect of ozone exposure on the ability of human surfactant protein a variants to stimulate cytokine production." Environmental Health Perspectives 110(1): 79-84.

Wang, K., J. Wang, C. L. Zhu, L. D. Yang, Y. D. Ren, J. Ruan, G. Y. Fan, J. Hu, W. J. Xu, X. P. Bi, Y. A. Zhu, Y. Song, H. T. Chen, T. T. Ma, R. P. Zhao, H. F. Jiang, B. Zhang, C. G. Feng, Y. Yuan, X. N. Gan, Y. X. Li, H. H. Zeng, Q. Liu, Y. L. Zhang, F. Shao, S. J. Hao, H. Zhang, X. Xu, X. Liu, D. P. Wang, M. Zhu, G. J. Zhang, W. M. Zhao, Q. Qiu, S. P. He and W. Wang (2021). "African lungfish genome sheds light on the vertebrate water-to-land transition." Cell 184(5): 1362-+.

Wang, S., L. Liu, J. Liu, W. Zhu, Y. Tanizaki, L. Fu, L. Bao, Y.-B. Shi and J. Jiang (2019). "Gene Expression Program Underlying Tail Resorption During Thyroid Hormone-Dependent Metamorphosis of the Ornamented Pygmy Frog Microhyla fissipes." Frontiers in Endocrinology 10.

Wang, S., L. Zhao, L. Liu, D. Yang, J. R. Khatiwada, B. Wang and J. Jiang (2017). "A Complete Embryonic Developmental Table of Microhyla fissipes (Amphibia, Anura, Microhylidae)." Asian Herpetological Research 8(2): 108-117.

Weaver, T. E. and J. J. Conkright (2001). "Function of Surfactant Proteins B and C." Annual Review of Physiology 63(1): 555-578.

Weaver, T. E. and J. A. Whitsett (1991). "Function and regulation of epression of pulmonary surfactant-associated proteins." Biochemical Journal 273: 249-264.

Weber, R., B. Blum and P. R. Muller (1991). "The switch from larval to adult globin gene expression in Xenopus laevis is mediated by erythroid cells from distinct compartments." Development 112(4): 1021-1029.

Wright, J. R. (2005). "Immunoregulatory functions of surfactant proteins." Nature Reviews Immunology 5(1): 58-68.

Zhou, Y., J. C. Horowitz, A. Naba, N. Ambalavanan, K. Atabai, J. Balestrini, P. B. Bitterman, R. A. Corley, B. S. Ding, A. J. Engler, K.

C. Hansen, J. S. Hagood, F. Kheradmand, Q. S. Lin, E. Neptune, L. Niklason, L. A. Ortiz, W. C. Parks, D. J. Tschumperlin, E. S. White, H. A. Chapman and V. J. Thannickal (2018). "Extracellular matrix in lung development, homeostasis and disease." Matrix Biol 73: 77104. 